\title{
A community diagnostic tool for chemistry climate model validation
}

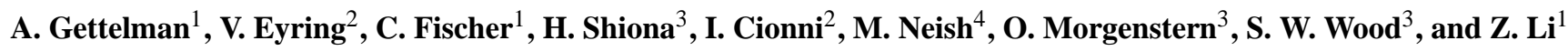 \\ ${ }^{1}$ National Center for Atmospheric Research, Boulder, CO, USA \\ ${ }^{2}$ Deutsches Zentrum für Luft- und Raumfahrt (DLR) Institut für Physik der Atmosphäre, Oberpfaffenhofen, Germany \\ ${ }^{3}$ National Institute for Water and Atmosphere Research, New Zealand \\ ${ }^{4}$ University of Toronto, Toronto, ON, Canada \\ Correspondence to: A. Gettelman (andrew@ucar.edu)
}

Received: 18 April 2012 - Published in Geosci. Model Dev. Discuss.: 11 May 2012

Revised: 16 July 2012 - Accepted: 2 August 2012 - Published: 3 September 2012

\begin{abstract}
This technical note presents an overview of the Chemistry-Climate Model Validation Diagnostic (CCMValDiag) tool for model evaluation. The CCMVal-Diag tool is a flexible and extensible open source package that facilitates the complex evaluation of global models. Models can be compared to other models, ensemble members (simulations with the same model), and/or many types of observations. The initial construction and application is to coupled chemistry-climate models (CCMs) participating in CCMVal, but the evaluation of climate models that submitted output to the Coupled Model Intercomparison Project (CMIP) is also possible. The package has been used to assist with analysis of simulations for the $2010 \mathrm{WMO} / \mathrm{UNEP}$ Scientific Ozone Assessment and the SPARC Report on the Evaluation of CCMs. The CCMVal-Diag tool is described and examples of how it functions are presented, along with links to detailed descriptions, instructions and source code. The CCMVal-Diag tool supports model development as well as quantifies model changes, both for different versions of individual models and for different generations of community-wide collections of models used in international assessments. The code allows further extensions by different users for different applications and types, e.g. to other components of the Earth system. User modifications are encouraged and easy to perform with minimum coding.
\end{abstract}

\section{Introduction}

The future evolution of ozone, climate and air quality are coupled and depend on interactions between atmospheric chemistry, dynamics, and radiation (Brasseur and Roeckner,
2005). For example, near the surface, changes in climate (temperatures, transport, and clouds) may strongly affect air pollution, and, in the upper troposphere and lower stratosphere, changes to radiatively active chemical species (ozone, water vapor, methane, clouds) may affect climate. Coupled chemistry-climate models (CCMs) are the main tool for studying these processes and for providing projections for national and international assessments, such as the United Nations Environment Programme (UNEP)/World Meteorological Organization (WMO) Scientific Assessments of Ozone Depletion. Evaluating these models is a difficult task. The models need to be tested against climate and chemistry observations. Comparisons between models are also difficult due to intrinsic model differences (e.g. model resolution, differences in the dynamical cores and chemistry schemes), model complexity and feedbacks in the climate and chemical system. Because of this complexity, it is vital to understand these models on a process by process level to ensure that model simulations match observations for the right reasons. Significant effort has gone into development of model intercomparisons to compare models to observations and each other for assessment of climate change (Meehl et al., 2007) and ozone depletion (Eyring et al., 2006; SPARC-CCMVal, 2010). Over time, model intercomparison projects have seen the emergence of ever more complex diagnostics and tests to measure model performance. Such added complexity in model evaluation calls for the development of a standardized package used throughout the community, to assess the performance of models individually and as groups, and to trace their evolution over time using consistent, standardized diagnostics. 
This technical note documents a diagnostic package for CCMs, the Chemistry Climate Model Validation Diagnostic (CCMVal-Diag) tool. The CCMVal-Diag tool facilitates comparisons between models, and between models and observations. The diagnostic tool is an integrated part of the larger international CCMVal effort to improve model representations of stratospheric chemistry and climate (SPARCCCMVal, 2010).

The CCMVal-Diag code is open source, extensible and flexible. In principle, the code is generic, and new variables representing other parts of the Earth system can easily be analyzed. It can analyze multiple models (where "model" is a given code used for a simulation) or multiple ensembles of a single model (using the same code). The code can produce performance metrics and is designed to enable comparison of models to observations. Examples are shown for global grids, but any gridded output (for example from limited area regional models) can be analyzed in the same way. It is designed to be easy for a user to modify and customize the tool.

The current version of the diagnostic tool (version 3) is designed to convert model output to the Climate and Forecast (CF) metadata compliant CCMVal-2 data standard (see Sect. 2.2) and to produce standard diagnostics. More information about the CCMVal-2 data standard is provided through links in Appendix A. This version specifically works with CCMVal-2 model output, but also will process the output used for the Coupled Model Intercomparison Project (CMIP) versions 3 and 5. The CCMVal-Diag tool has been used for analysis of CCMs in the SPARC-CCMVal (2010) report and World Meteorological Organization (2010) Scientific Assessment of Ozone Depletion.

This technical note is organized as follows. A basic code description is provided in Sect. 2. Section 3 describes how to run and modify the tool. Some examples of how the tool can be used for developing simple and complex diagnostics for global chemistry and climate models compared to observations and each other are presented in Sect. 4, and a summary in Sect. 5. The CCMVal-Diag tool source code, observational data sets and links to model output are available via the website listed in the Appendix. A more detailed set of instructions for installing and running the tool, as well as versioning and references, is available in a "readme" file in the source code distribution.

\section{CCMVal-Diag structure}

\subsection{Principles}

Several overall principles have guided the development of the CCMVal-Diag tool. The code is designed to compare models to each other and to observations. The purpose is to elevate the standard of process-oriented evaluation of global models, particularly chemistry-climate models, over time. The diagnostics should be traceable: the code is kept in an archive, and users are encouraged to upload (see Appendix A) their own diagnostics and improvements to existing diagnostics, to become part of the tool. Diagnostics should be repeatable as new models (or versions of models) are developed or new observations are added. Observations enter the tool in a processed manner, and multiple observations for the same diagnostic or species can be included. The tool is modular and extensible: it can be used to run a single diagnostic or many diagnostics. Diagnostics can be as simple as direct translation of model output, to highly derived and calculated quantities based on multiple variables. The version of the diagnostic tool described here will process output at any time frequency, but is designed for monthly time series.

The tool is based on a minimal set of open source packages available on many platforms. The CCMVal-Diag code is designed so that users can edit (hack) the tool with minimum programing experience, by following examples.

\subsection{Basic description}

The CCMVal-Diag code is based on Python and the National Center for Atmospheric Research (NCAR) Command Language (NCL) scripting language. It requires these two packages to be installed (see Sect. 2.3). It takes as input either (a) raw model output or (b) Network Common Data Format (NetCDF) files in CCMVal-2 data request format (Eyring et al., 2008). If (a), it can process model output into (b) with code written for a specific model (see Sect. 3.1). CCMVal-2 data format is $\mathrm{CF}$ compliant with standard variable names. The CCMVal-2 standard differs in that it adds some additional metadata and coordinate descriptions (such as time and date arrays) not required by $\mathrm{CF}$.

The tool can be used to convert "raw" model output to CF compliant output. Customization is required for each model to get output into the CF format. This initial release comes with code for translating NCAR Community Climate System Model (CCSM) format NetCDF files as a template. Each model will need its own piece of code to do this.

The code will read files compliant with the CF NetCDF CCMVal-2 format. However, there are some models with slightly incompatible formats due to improper use of the specification. An example might be an offset in the time dimension, or the wrong units for the pressure field. A flexible mechanism in the code allows model-specific changes to be added easily as they are discovered, by adding a function to fix data for a specific model and project (CCMVal2, CMIP5). CCMVal-2 model output is available from the British Atmospheric Data Center (BADC). For more details about obtaining CCMVal-2 model data, see the links in Appendix A.

The code can also read climate model output submitted to CMIP, since CMIP5 and CCMVal2 both use CF format. CMIP5 model output is produced with the CMOR package (Taylor et al., 2012). We show an example using several CMIP5 models in Sect. 4. 


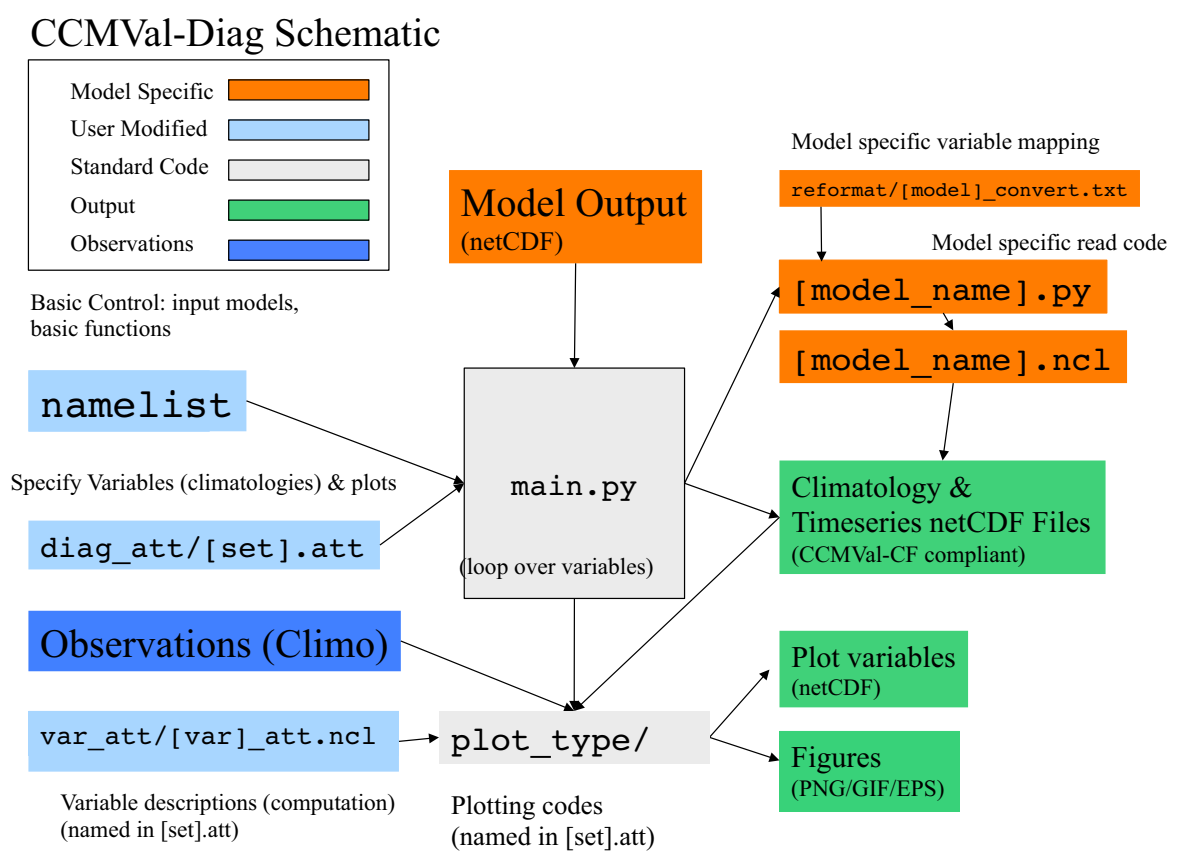

Fig. 1. Schematic figure depicting the operation of the CCMVal-Diag tool as described in the text.

The code will further create climatology and time series files for the specified variables, and create publication quality (postscript) figures. Figures 2 through 8 were produced with the tool.

The operation of the tool is illustrated schematically in Fig. 1. The basic control is in Python. Python is used as a scripting layer to parse namelists and call NCL code. NetCDF file input/output, variable manipulation and plotting are all handled by NCL, requiring no extra libraries or configuration. The basic operation is to call the main Python routine and pass it a namelist file. The namelist specifies (a) global flags, (b) model output to process and (c) a file of diagnostic sets to run. The diagnostic sets (diag_att/[set] . att) specify the diagnostics to process.

A "diagnostic" in the CCMVal tool has two components: a variable ([var]) and a plot (plot_type) routine. Variable descriptions are contained in a variable attributes directory (var_att). New variables are placed here as well. The code looks for a variable attribute file (var_att/[var]_att.ncl). Variable names are either standard names from the CCMVal-2 CF specification, or "derived" variables. Derived variables are functions of other variables. Each variable name must have a variable attribute file. The variable attribute file contains NCL code for processing derived variables. This can be as simple as changing units (e.g. multiplying by a constant or field), or a combination of other variables. For example, the lapse rate tropopause temperature (or other properties) can be calculated based on a set of temperature profiles. The variable attribute file also sets attributes used to run different plotting routines for the variable (for example, defining a text name and units, and contour intervals). These attributes are used by specific plotting routines.

The second component of a diagnostic is a plotting routine. The plotting routines are NCL routines in the plot_type directory. For the example of the tropopause temperature cited above, it can be plotted in many ways: a zonal mean, a trend in some region or season over time, a map of the temperature or a map of trends, etc. These "plot types" are discussed in Sect. 4. Specific plotting attributes, such as axis ranges or contour intervals, can be specified in the variable attributes file for each variable and plot type. The diagnostic code can send the inputs to a plotting routine, or save a processed variable to a file in a standard format. For example, tropopause temperature can be saved to a CCMVal-2 CF compliant NetCDF file that looks like any other input variable to the diagnostics so that computation needs only occur once.

A standard set of file naming conventions indicates the dimension of variables in the file. The convention is an extension of the CCMVal2 data request convention. The naming convention has 4 parts: type, number, averaging and (optionally) reduction. Type is either $\mathrm{T}=$ Timeseries or $\mathrm{C}=$ climatology (indicating the time dimension). Number indicates the number of spatial dimensions $(0=$ global, $2=$ latitude-longitude or latitude-level, $3=$ latitude, longitude, level). Averaging is either $\mathrm{M}=$ monthly, $\mathrm{D}=$ daily, $\mathrm{A}=$ annual or $\mathrm{I}=$ instantaneous. Reduction indicates a data reduction if necessary, where $s=$ surface 

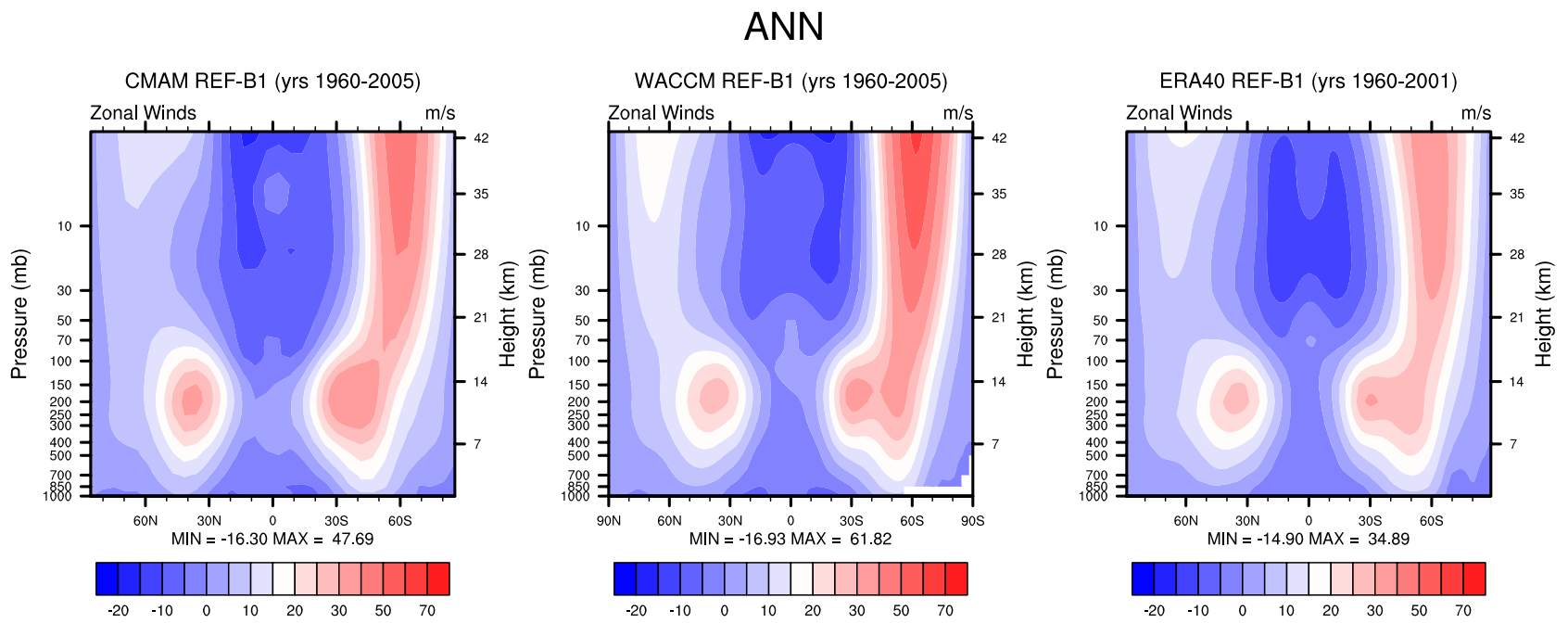

Fig. 2. Zonal mean zonal wind averaged for 1980-1990 from two historical (REF-B1) model simulations (left and center) included in the CCMVal-2 archive and ERA40 reanalyses (right). Models are the Canadian Middle Atmosphere Model (CMAM-Left) and the Whole Atmosphere Community Climate Model (WACCM-Center). The height values are a logarithmic interpolation from standard atmosphere of the pressure.

(latitude-longitude) and $\mathrm{z}=$ zonal mean (latitude-level). For example, a zonal monthly mean time series is indicated as $\mathrm{T} 2 \mathrm{Mz}(\mathrm{T}=$ timeseries, $2=$ number of dimensions, $\mathrm{M}=$ monthly mean, $\mathrm{z}=$ zonal mean). Monthly means of a 3-D variable (latitude, longitude, altitude) are indicated as T3M. Once the variable is processed for each model, a standard data structure is passed to the plotting routines in the plot_type directory. These routines produce graphics and standard output (such as trend calculations or performance metrics) as well as have the option to produce files containing the data on the plot (noted as "Plot variables" in Fig. 1).

The code is set up to read in NetCDF files with either one time sample per file or multiple time samples per file. It can also concatenate variables across multiple files. Examples of reading one and multiple time samples per file are contained in the sample read code for CCSM.

\subsection{Installation}

The CCMVal-Diag tool has been designed to use a minimum of open source packages, and no proprietary software. Installation of the code requires only Python and NCL. The CCMVal-Diag tool requires basic Python for the driver layer (Fig. 1). The code has been tested with Python version 2.3.4 and should run with 2.3.4 or later. Python source code and binaries for most systems are available from the Python project (www.python.org).

The CCMVal-Diag tool uses NCL for most of its processing (manipulating NetCDF files) and for preparing graphics. NCL is also an open source package, with binaries for many systems (AIX, IRIX, Linux, MacOSX, Solaris, Windows).
The code requires NCL version 5.1.0 or later (www.ncl.ucar. edu).

\subsection{Observations}

Comparisons between simulations and observations are a critical part of model evaluation, and the CCMVal-Diag tool has been designed to easily incorporate observations in qualitative and quantitative evaluation. Observations enter the tool in two ways: either as another "model" or as a separate plotspecific data file.

In the first method, observations can be converted into a format identical to the models. This can be done if the observations are available in gridded format for a defined time period. Reanalyses are the most common type of such "observations", or long-term or multi-satellite records. Several examples of such observations are shown in Sect. 4 (e.g. Fig. 2). In these cases, the observations are listed in the namelist as another model.

Another method is to tailor observations for specific comparisons. In this method, often a climatology from a specific observation type is processed for a specific type of plot, and written in the plot_type code. Such observations are specified as attributes for a specific variable, usually for a specific plot type. This method is also illustrated in Sect. 4 (Figs. 7 and 8; see below).

Both methods could be combined: for example, a tropopause climatology for the tropics could be plotted for comparison with models, but the tropopause could also be calculated from an analysis or gridded radiosonde record input as another model. 


\section{Processing methods}

In this section, we describe the different processing methods that the CCMVal-Diag tool provides, and ways to use the tool.

\subsection{Converting model output}

In general, global models write data sequentially, with many variables for individual time samples, in files with single or multiple time samples. For intercomparison projects, typically files with multiple time samples and a single variable are desired to reduce output size, and for ease of processing. The CCMVal-Diag tool provides a framework and examples for processing of model output into correct formats for intercomparisons. It can also be used to check formatting conventions. Currently, the most commonly used format is the $\mathrm{CF}$ compliant NetCDF standard, and the tool is designed to read this (and optionally write).

The CCMVal-Diag tool will process model output and generate two types of files: time series files (T3M, T2Ms, etc) which contain one variable at all times. The type specification follows the CCMVal- 2 convention described earlier. The code also makes "climatology files" (C3M, etc) that are used internally for plotting, or in further post-processing. Timeseries files are in CCMVal-2 CF compliant NetCDF format.

For processing of model files, the code requires 3 files (orange in Fig. 1): (a) a Python driver to find the files, (b) an NCL code to process the files and (c) a text file to remap model variable names to $\mathrm{CF}$ compliant CCMVal-2 format variable names. The Python code (modelname.py) sets the filenames, gets the variable names, and then calls the NCL processing code (modelname. $\mathrm{ncl}$ ). The NCL processing code performs operations on the file list to concatenate files together. For the initial conversion implementation with the NCAR CCSM, the raw model output files are NetCDF files, but the structure will work on any other file type that NCL can read. The user can supply NCL code to read a specific raw model output in any format (binary, GRIB, HDF, ASCII, etc), and the tool will then process the files to CF compliant format. A utility for checking CF compliance is also included in the tool.

\subsection{Comparing models to observations}

Model comparisons to observations use one of the two methods described in Sect. 2. Basically, these methods involve pre-processing the data to be interpreted as a separate model, or further processing to produce data directly for plotting. An example of the first type, data processed like a model, might be for a gridded satellite product, where 2-D (zonal or a surface) or 3-D monthly means can be produced in the CCMVal-2 format. Another example is a reanalysis data set such as the ERA40 reanalysis (Uppala et al., 2005) shown in Fig. 2. Further examples are shown in Sect. 4. The second type would be a more heavily processed data set, read in for a specific variable and a specific plot. This could be an annual climatology file (monthly climatology of water vapor in 2-D or 3-D), such as used from the HALOE satellite in Fig. 7. The diagnostic tool can even use specific values of a derived product (for example, meridional heat flux, defined as the product of anomalies of zonal wind $\left(v^{\prime}\right)$ and temperature $\left(T^{\prime}\right)$ ). These multiple methods allow flexibility. Both methods could be used in common for the same variable.

\subsection{Comparing models to each other}

In addition to comparing models to observations, the CCMVal-Diag tool is designed to compare models to each other. The number of models is arbitrary. Model names (and a standard set of colors and line styles) for CCMVal models have been included in the CCMVal-Diag tool, but models without a known name will still be processed. The names and number of models are simply read from the namelist. Each run or ensemble member is treated separately. Multiple ensemble members from a single model can be processed. Each ensemble member can have different start and end dates. Some diagnostics require full years for processing. Many diagnostics can take a "reference" model (or observation) for difference plots. Model output from different scenarios can be placed on the same plot, such as a historical run and a future scenario, or two different future scenarios. The standard CCMVal-2 model set contains up to 18 models, some with ensemble members available.

Models can have their own grids (e.g. Fig. 3). In principle, models need not have a full global grid either (limited area models can be processed). Difference plots interpolate and regrid for comparison purposes.

\subsection{Quantitative trends and performance metrics}

Several of the plotting routines are designed to plot time series, and these plots also produce quantitative estimates of trends. Trends can be calculated using any method desired. Currently, several of the routines provide trends based on linear regression with significance testing, providing quantitative trends as well as confidence intervals. Trends can also be used as a diagnostic, for example plotting trends on a map (see Sect. 4).

Another complex aspect of model intercomparison is provided by the calculation of performance metrics. A performance metric is defined as a quantitative measure of agreement between a simulated and observed quantity, which can be used to assess the performance of individual models (Knutti et al., 2010). These evaluations are complex, and dependent on the choice of diagnostics used. Several statistical measures for quantitative metrics comparing models to observations have been built into the CCMVal-Diag tool for specific purposes. An example is provided in Sect. 4.3. 
JJA

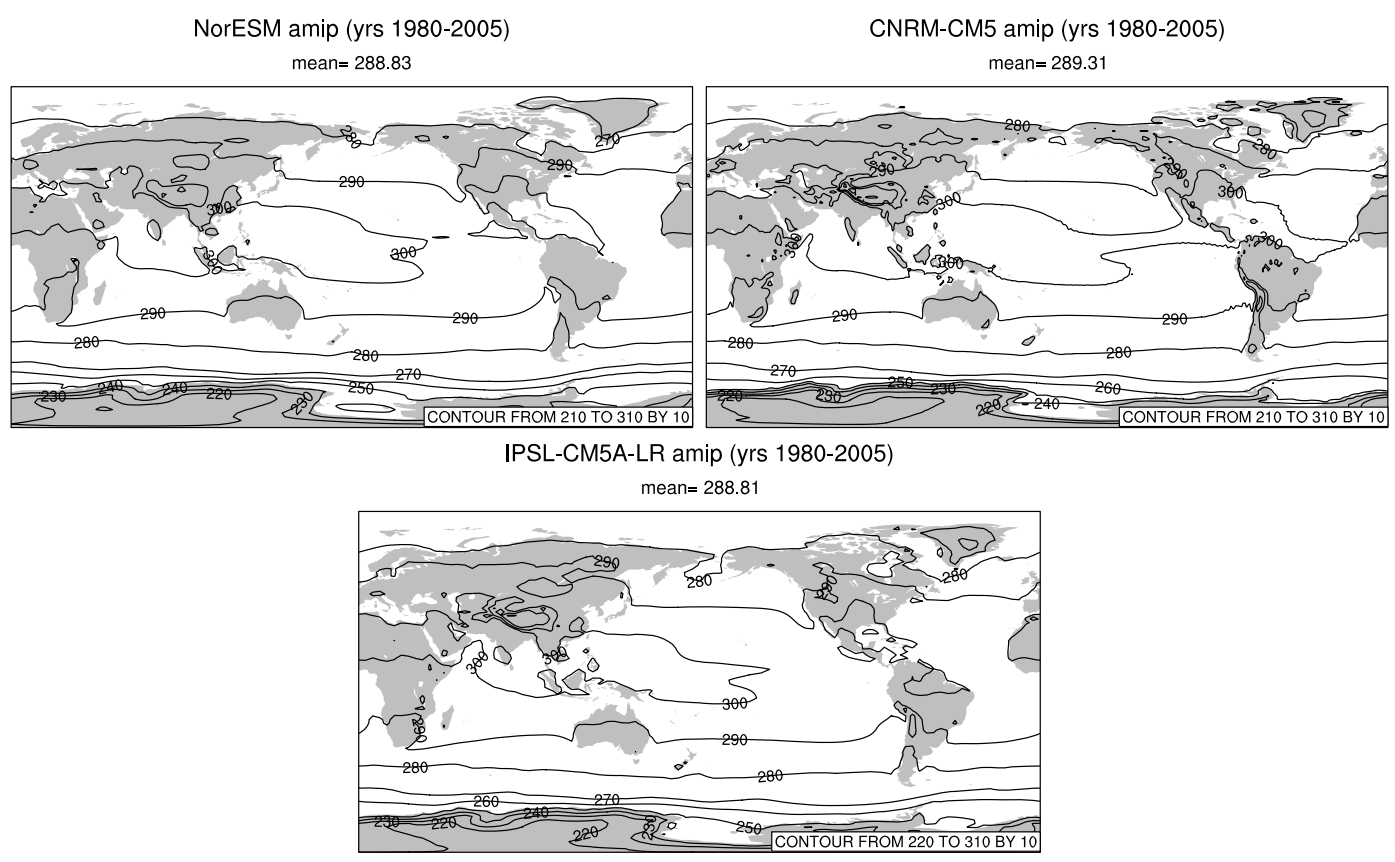

Fig. 3. Contour plot of June-August surface air temperature (K) for "historical" (AMIP) runs from three models that are part of CMIP5. Averages are from 1980-2005 for the Norwegian Earth System Model (NorESM), the Centre National de Recherches Météeorologiques Model (CNRM-CM5) and the model of the Institut Pierre Simon Laplace (IPSL-CM5A-LR).

\subsection{Developing new diagnostics and observations}

Developing new diagnostics within the CCMVal-Diag code requires adding new variable descriptions and/or new plotting codes, and calling them in diagnostic set file. To develop a new diagnostic "variable" (i.e. newvar), all that is needed is to define it with a new variable attributes file (var_att/newvar_att.ncl). This can be a simple read command, or a derived variable with some processing. Variables can have any name; the code simply looks to see if the file exists. Then the variable can be plotted with a general or custom plot type. If necessary, new plot types can be added (to the plot_type directory). However, often standard plot types can be used with new variables. The variable and plot type (or multiple plot types for a variable) are specified by a diagnostic set (diag_att/ [set] . att) file, called from a namelist.

Adding new diagnostics also includes adding new observations. As noted, observations can be introduced into the tool in two ways. Observations can be formatted to look like another model, or as a specific data set for a particular plot, coded directly into the plot type. Both methods use attributes (such as a file path) set in the variable attribute file. Section 4 illustrates both methods.

The overall principle is that the code should be easily extensible.

\subsection{Documentation, versions, and metadata}

Ensuring the documentation and traceability of the diagnostics is an important part of the CCMVal-Diag tool. Detailed documentation is contained in a "README" file that is part of the tool code. This includes a revision history. The code is being maintained in a revision-controlled repository, which also logs changes. An archive will hold release versions of the tool, which will contain their own documentation. Since one goal is to encourage community (user) development, users are encouraged to submit their own or updated diagnostics. Metadata in these diagnostics, including detailed metadata on observations used in the tool, will be required. This will include references to diagnostics in the published literature. Metadata for observations will be discussed in the routines where the observations are called (with appropriate references), and in metadata of the observation files themselves. There is no specific standard in the tool yet for observational metadata beyond appropriate references and sufficient metadata for scientific reproducibility.

\section{Examples}

In this section, we provide several examples illustrating the concepts above, as well as a list of plot types currently available as part of the tool. There are two classes of plots. The first are generic plot types for different types of 1-D and 2-D 


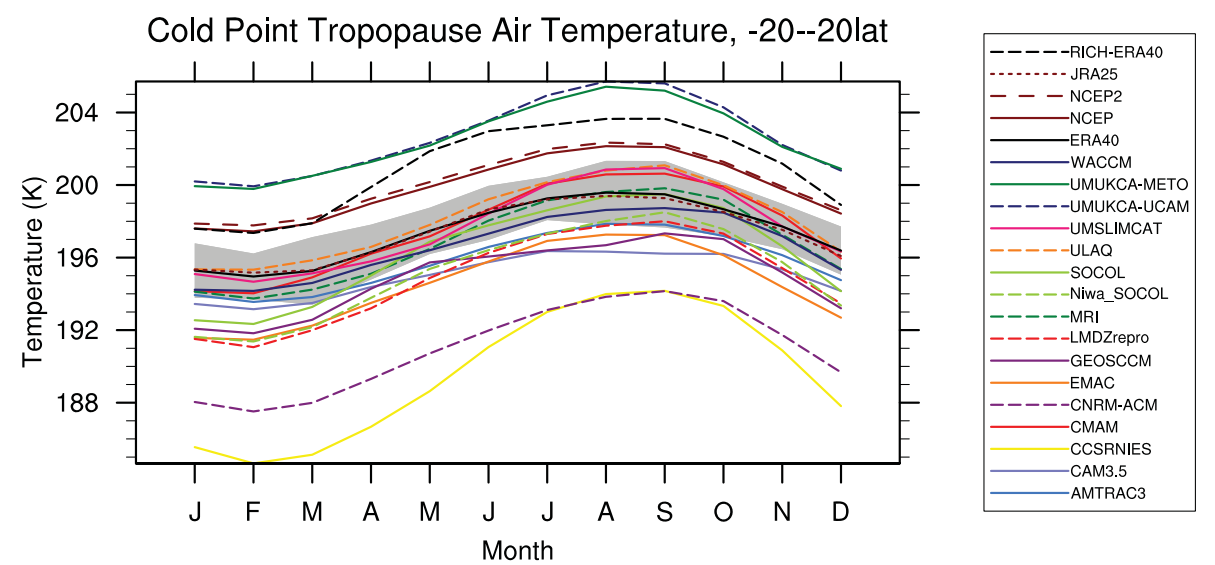

Fig. 4. Cold point tropopause temperature annual cycle from CCMVal-2 models and several re-analysis (ERA40, NCEP, NCEP2, JRA25) and processed radiosonde (RICH-ERA40) data sets. Gray region indicates 2 standard deviations around the ERA40 (black solid line) reanalysis.

plots. As noted, these can range from simple to complex, as discussed in the next sub-section. There are also specialized plots designed to be run as a set repeatedly on sets of models to gauge changes. These involve additional processed observations and are noted below.

\subsection{General plot types}

Table 1 lists key plot types coded into the tool. Many of these plotting routines in NCL were modified from the CCSM Atmospheric Model Working Group Diagnostic Package (http://www.cgd.ucar.edu/amp/amwg/diagnostics/). Plots range from line plots, to linear trend plots, to contour plots. Cylindrical and polar map projections are available (as well as many others in NCL). These plot types also all are able to produce output data in NetCDF format instead of producing a plot in case further processing is desired. Difference plots are available for most of the types, which compare models against a reference model (or gridded data set) and interpolate grids as needed. A few key examples are given below.

Figure 2 illustrates a simple diagnostic using the "vertconplot" routine: the zonal mean zonal wind from two models compared to observations. Contours can be automatically generated, or specified for each variable and plot type individually. In this case the observation (ERA40 data) is preprocessed to conform to the CCMVal-2 NetCDF output specification, and read in like a model. In addition to annual mean plots, the vertconplot routine also produces DecemberFebruary and June-August seasonal plots. Seasons can be customized and adjusted (e.g. January-March can be plotted instead).

Figure 3 illustrates a surface contour plot ("surfconplot") for seasonal (boreal summer, June-August) surface air temperature from three model simulations. These model simulations are from the CMIP5 archive. The files were renamed to match CCMVal naming conventions, but the tool can read and plot the files. Extension of the tool to read different model archives in CF compliant format is thus simple. Different seasons can be selected. Note that the models have different horizontal grids.

A more complex diagnostic could be derived from a model variable. For example, Fig. 4 (derived from Gettelman et al., 2010) is produced with the "monline" plot type, illustrates the monthly climatology of tropical averaged cold point tropopause temperature from $20^{\circ} \mathrm{S}$ to $20^{\circ} \mathrm{N}$ from 16 CCMVal-2 models (see Morgenstern et al., 2010 for an overview of the models), 4 analysis systems (JRA25, NCEP2, NCEP, ERA40) and a radiosonde reconstruction (RICH-ERA40). Several different features of the tool are illustrated. The derived variable for cold point tropopause temperature is calculated from monthly mean temperature profiles. The tropopause temperature is calculated each month (in this case from 1980-2004, or a subset if the analysis system does not have all the dates), area weighted (accounting for differences in area by latitude), and a monthly climatology created. ERA40 data are chosen as the reference time series, and the shaded region indicates 2 standard deviations from the monthly mean. This particular code also produces statistics for quantitative performance metrics based on the methodology of Gettelman et al. (2010) (see Sect. 4.3). Another feature of the tool is to output the processed variables in NetCDF format for use by other plotting packages. For example, in this case the code would output a NetCDF file with 21 variables (one for each model and observations), each with 12 values (one per month). This file could be used in another plotting package. The legend of models uses standard colors and line-styles by model name. These colors and line-styles can be altered, but defaults exist to facilitate comparison and commonality across diagnostics.

The CCMVal-Diag tool can also be used to calculate trends. Figure 5 illustrates trends in tropical averaged cold point temperature for the 20th and 21 st century from 
Table 1. General plot types.

\begin{tabular}{ll}
\hline Plot Name & Description \\
\hline noplot & no plot, convert only \\
save_to_netcdf & save timeseries of a variable \\
anncycplot & annual cycle of monthly zonal means \\
vertconplot & lat vs. height contour plot (3-D or 2-D zonal mean) \\
plrconplot & polar contour plot of a 2-D field \\
seacycplot & seasonal cycle line plot of seasonal cycle \\
seadiffplot & contour plot of seasonal difference DJF-JJA \\
tsline & timeseries plot: seasonal and annual, anomalies or full field \\
monline & annual climatology plots \\
surfconplot & 2-D surface contour plot \\
surfcontrend & surface contour plot of trends at each point \\
zonlnplot & zonal mean line plot \\
zonlntrend & zonal mean line plot of trends \\
profiles & vertical profiles at selected locations \\
\hline
\end{tabular}

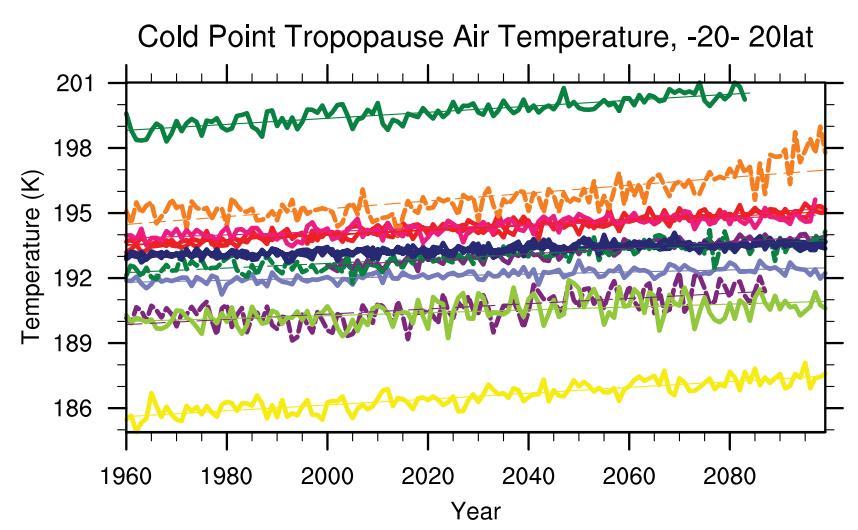

Fig. 5. Tropical cold point tropopause temperature trends from CCMVal-2 model simulations of the 21 st century. Thick lines are model values; thin lines are linear trends. Figure is similar to that in SPARC-CCMVal (2010) and Gettelman et al. (2010). Individual model colors and line-styles follow Fig. 4.

CCMVal-2 models (Gettelman et al., 2010) with the "tsline" routine. Here, $140 \mathrm{yr}$ of data are read in from 11 models. One model (CMAM: red) has two ensemble members, and one (WACCM: dark blue) has three ensemble members. The thin lines are linear fits to the data. Quantitative trends are written to standard output, with significance levels based on a twosided Student's t-test. Note that the ensemble members are nearly identical to each other.

Finally, diagnostics can be fairly complex and methods combined. As an example, we show in Fig. 6 a map (using the "surfcontrend" routine) of the trends in lapse rate tropopause pressure at each point from a CCM (WACCM) and ERA40 reanalysis temperatures for the historical period from 19602001. Here the code first calculates the tropopause pressure from temperature data (following Reichler et al., 2003) at each latitude and longitude, and then calculates a trend at each point. The trends are then plotted on a map. This shows how complex diagnostics can be used to layer on top of each other. The CCMVal-Diag tool can also easily plot differences between the models and a "reference" (such as the ERA40 reanalysis in Fig. 6), as necessary. Other routines can quantitatively compare zonal mean trends, illustrating the flexibility of the tool with a standard set of plot types.

\subsection{Repeatable diagnostics}

A strong principle for the CCMVal-Diag tool is supporting model development as well as quantifying model improvements, both for different versions of individual CCMs and for different generations of community-wide collections of models used in international assessments. Accordingly, the CCMVal-Diag tool has incorporated diagnostic plots to specifically evaluate processes important for stratospheric ozone. As a start, process-oriented diagnostics from Eyring et al. (2006) have been implemented into the structure so they can be repeated with different model versions. Table 2 lists the plot types. In principle these can be applied to any variable, but these plots are generally run with specific variables (noted in the table). The numbers refer to figure numbers in Eyring et al. (2006). Note that this also serves as an example of specifically documenting diagnostics for the tool.

Figure 7 shows water vapor profiles $(a, b)$ and the zonal mean at an altitude (c, d) from CCMVal-1 and CCMVal-2 models, following Fig. 5 of Eyring et al. (2006). HALOE satellite observations are shown as black dots. The individual models are the colored solid and dashed lines. Similar models (same model but a different version between CCMVal-1 and CCMVal-2) are shown with the same color and line style. Figures 7A and B clearly show that the spread of simulated water vapor at the tropical minimum (near $100 \mathrm{hPa}$ ) has narrowed in CCMVal-2. Several models have improved dramatically, such as the solid light blue (AMTRAC) and dashed 


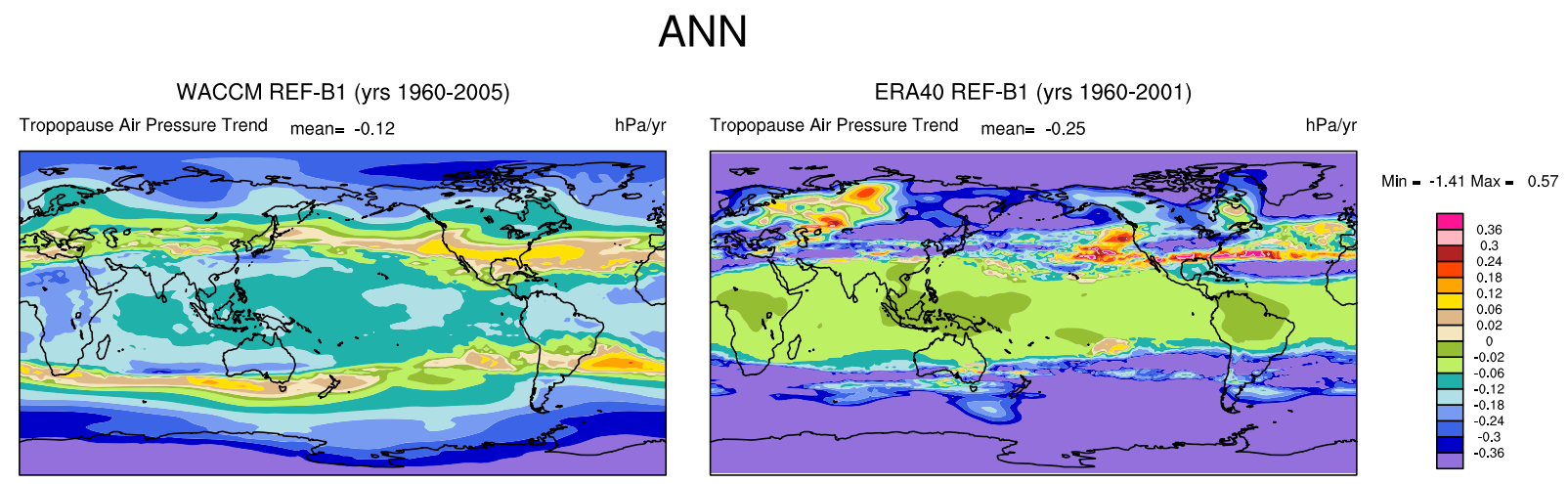

Fig. 6. Map of lapse rate tropopause pressure trends $\left(\mathrm{hPa} \mathrm{yr}^{-1}\right)$ from WACCM CCM and ERA40 reanalysis temperatures.

Table 2. Repeating plot types from Eyring et al. (2006).

\begin{tabular}{llll}
\hline Number & Short Name & Variables & Description \\
\hline 1 & vertline & $T$ & Line plot of vertical profile differences \\
2 & windzero & $U$ & zero wind line descent in pressure \\
4 & linets & $T$ & 1-D timeseries plot (like tsline) \\
$5 \mathrm{a}$ & vertval & $\mathrm{O}_{3}, \mathrm{CH}_{4}, \mathrm{H}_{2} \mathrm{O}, \mathrm{HCl}$ & zonal mean profile plot \\
$5 \mathrm{~b}$ & meridval & $\mathrm{O}_{3}, \mathrm{CH}_{4}, \mathrm{H}_{2} \mathrm{O}, \mathrm{HCl}$ & zonal mean line plot \\
7 & linemon & $T, \mathrm{H}_{2} \mathrm{O}$ & annual cycle line plot (like monline) \\
8 & vertts & $\mathrm{H}_{2} \mathrm{O}$ & vertical profiles over time \\
9 & vertamp & $\mathrm{H}_{2} \mathrm{O}$ & amplitude and phase lag in vertical \\
12 & profilets & $\mathrm{Cly}$ & profile and timeseries line plots (2 panel) \\
14 & surfann & Column $\mathrm{O}_{3}$ & contour plot of a 2-D zonal mean over month \\
15 & tsclimo & Column $\mathrm{O}_{3}$ & combination of timeseries and climatology \\
\hline
\end{tabular}

gray (E39C) models. This improvement is also seen in the zonal mean at $50 \mathrm{hPa}$ (Fig. $7 \mathrm{c}$ and d). These results are used extensively to compare CCMVal-1 and CCMVal-2 models in the SPARC report on the evaluation of chemistry-climate models (SPARC-CCMVal, 2010).

Figure 8 shows the inorganic chlorine $\left(\mathrm{Cl}_{\mathrm{y}}\right)$ climatological mean vertical profile $(A, C)$ and the time series $(B, D)$ of 11 CCMVal-1 models (lower panel) and 12 CCMVal-2 models (upper panel) similar to Fig. 12 of Eyring et al. (2006). $\mathrm{Cl}_{\mathrm{y}}$ is a strong indicator of chlorine-induced ozone loss, and the rise in $\mathrm{Cl}_{\mathrm{y}}$ from 1980 to 2000 and subsequent decline are a key metric for understanding the ozone hole. Observations are specified as attribute of the specific plot type. This routine can easily be used for any other chemical variable. Observations of $\mathrm{Cl}_{\mathrm{y}}$ are derived from $\mathrm{HALOE} \mathrm{HCl}$ measurements in 1992 and Aura MLS HCl in 2005 as described by Eyring et al. (2006).

\subsection{Quantitative metrics}

Finally, the diagnostics and code can be used to develop quantitative grades for model performance. Quantitative performance evaluation is highly dependent on the choice of diagnostics used. Here we merely show an example of how the CCMVal-diag tool has been used to derive several such metrics. Following Waugh and Eyring (2008) and Gettelman et al. (2010), we show quantitative metrics for CCMVal2 models in the upper troposphere and lower stratosphere (UTLS) in Fig. 9. These quantitative metrics compare model climatological means to different observations of winds, temperatures and trace species (see Gettelman et al., 2010 for details). The figure is derived from Fig. 7.39 of SPARCCCMVal (2010). In this figure, grades from 0 to 1.0 were produced by the diagnostics tool by comparing model output to observations, and the results gathered into Fig. 9. Grades for the multi-model mean (MMM) are also calculated by the tool. The darker the color in Fig. 9 is, the better the model score. Variations on the overall bias metrics in Fig. 9 can also be easily added. These include statistical tests like rootmean-square (RMS) differences and "Taylor" diagrams of normalized errors and correlations.

\section{Summary and future plans}

The CCMVal diagnostic (CCMVal-Diag) tool has been developed to facilitate the evaluation of complex global models. The tool is now operational and allows for processing of simple and complex diagnostics simulated with global models. It can be used to evaluate single models (or different 

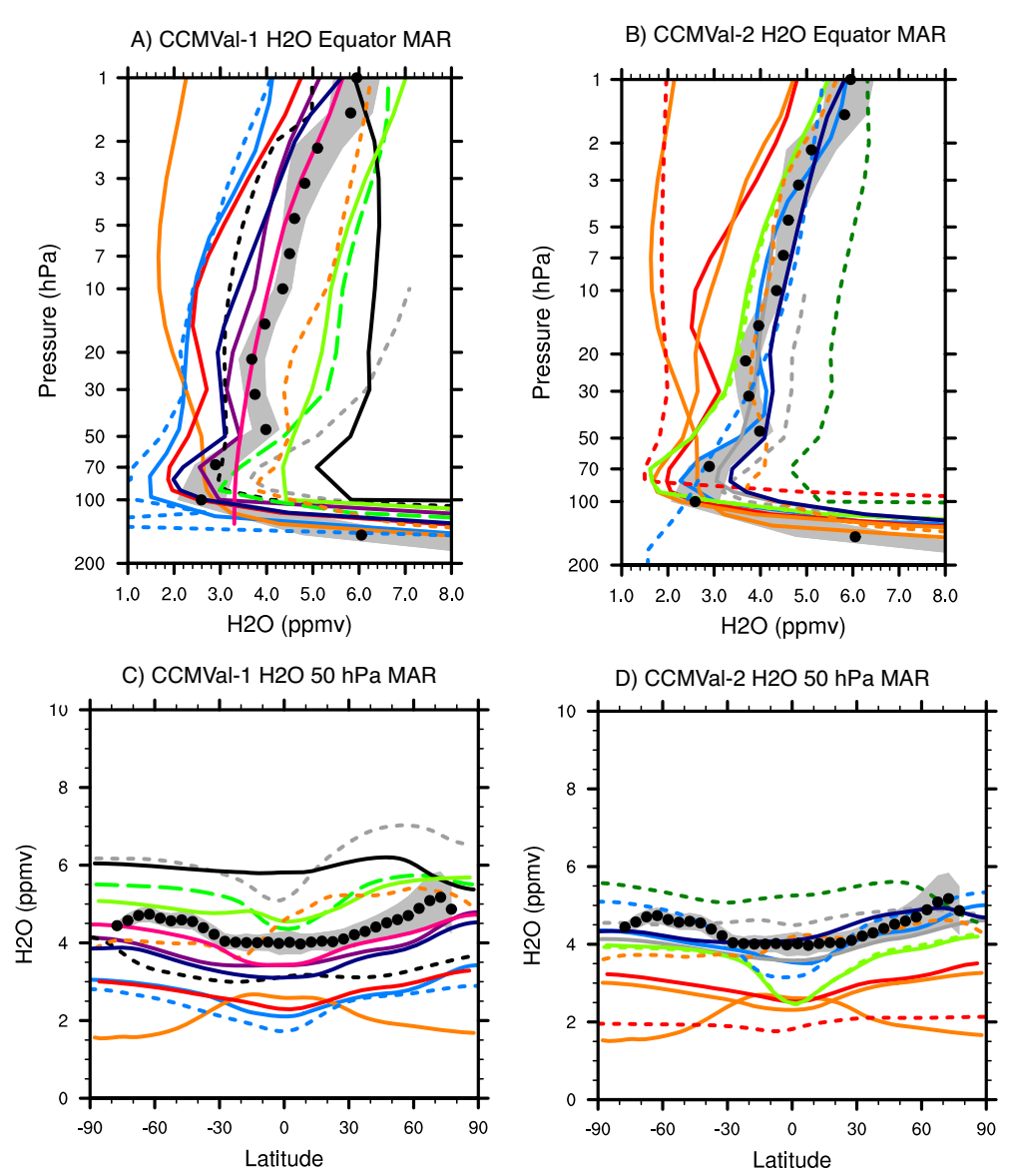

Fig. 7. Comparison of March water vapor concentration simulated for the 1990s by models from CCMVal-2 (B, D) and CCMVal-1 (A, C) for equatorial water vapor profiles $(\mathbf{A}, \mathbf{B})$ and zonal mean $50 \mathrm{hPa}(\mathbf{C}, \mathbf{D})$. HALOE observations are shown as black dots, and the gray shading is one standard deviation. Individual model colors and line-styles follow Figure 4.

versions of a model) against observations. It can also be used to evaluate the output from multiple models against observations and/or against each other, e.g. chemistry-climate models (CCM) participating in the CCM Validation (CCMVal) activity and climate models participating in the Coupled Model Intercomparison Project (CMIP).

The tool has the following features:

- Open Source

- Converts model output to standard format

- Analyzes and plots output

- Works on multi-model or single-model ensembles

- Integrates observations in multiple ways

- Flexible and Extensible

The tool has been used in several papers (Gettelman et al., 2010; Eyring et al., 2010a,b; Cionni et al., 2011), and has supported some of the analysis of SPARC-CCMVal (2010) and the World Meteorological Organization (2010) scientific assessment of ozone depletion. It will operate on standard CF compliant NetCDF model output, the standard format used by CCMVal and CMIP.

The diagnostic code could easily be extended to cover Earth system models (ESMs). In principle, any 2-D (surface, zonal mean) or 3-D field can be processed and plotted, regardless of grid (whether land surface, ocean, etc), global or regional. Additional observations for the existing diagnostics or for new diagnostics can be easily implemented, allowing a comparison to multiple measurements if available. The code thus allows further extensions by different users for different applications and types of ESMs. These applications could, for example, include the verification of decadal climate predictions, and the evaluation of aerosols, land surface or ocean parameters. The code also principally works for limited area (e.g. regional climate) models.

User modifications are encouraged and easy to perform with a minimum of coding. For example, defining a new diagnostic is simply a matter of knowing the variable names, some minimum coding for transforming the variables, and 

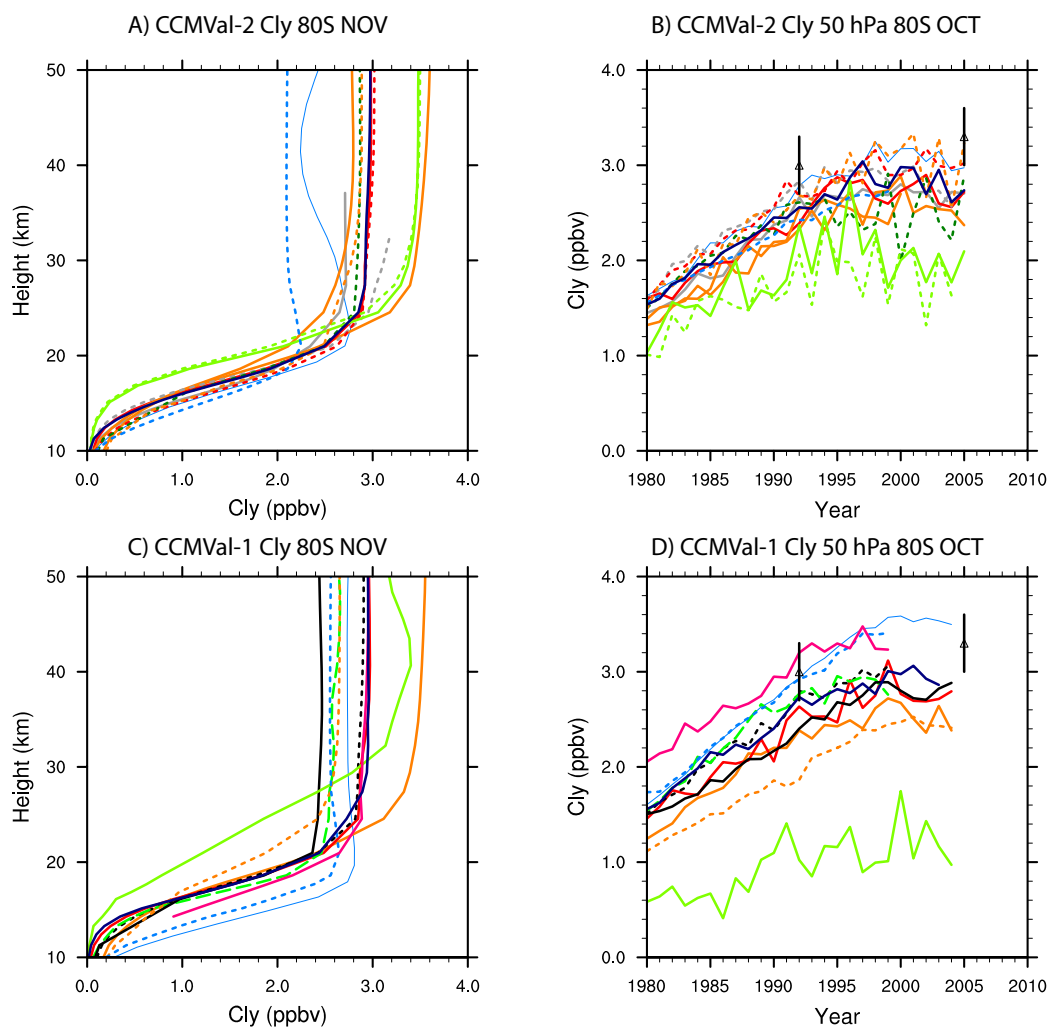

Fig. 8. $80^{\circ} \mathrm{S} \mathrm{Cl}_{\mathrm{y}}$ November profile (A, C) and October time series (B, D) for $11 \mathrm{CCMVal}-1$ models $(\mathbf{C}, \mathbf{D})$ and $12 \mathrm{CCMVal}-2$ models $(\mathbf{A}$, B). (A, C) Climatological mean vertical profiles (1990 to 1999) at $80 \mathrm{~S}$ in November for $\mathrm{Cl}_{\mathrm{y}}$ in ppbv. (B, D) Time series of October mean Antarctic $\mathrm{Cl}_{\mathrm{y}}$ at $80^{\circ} \mathrm{S}$ from CCM model simulations. Estimates of $\mathrm{Cl}_{\mathrm{y}}$ from $\mathrm{HALOE} \mathrm{HCl}$ measurements in 1992 and Aura MLS HCl in 2005 are shown. Individual model colors and line-styles follow Fig. 4.

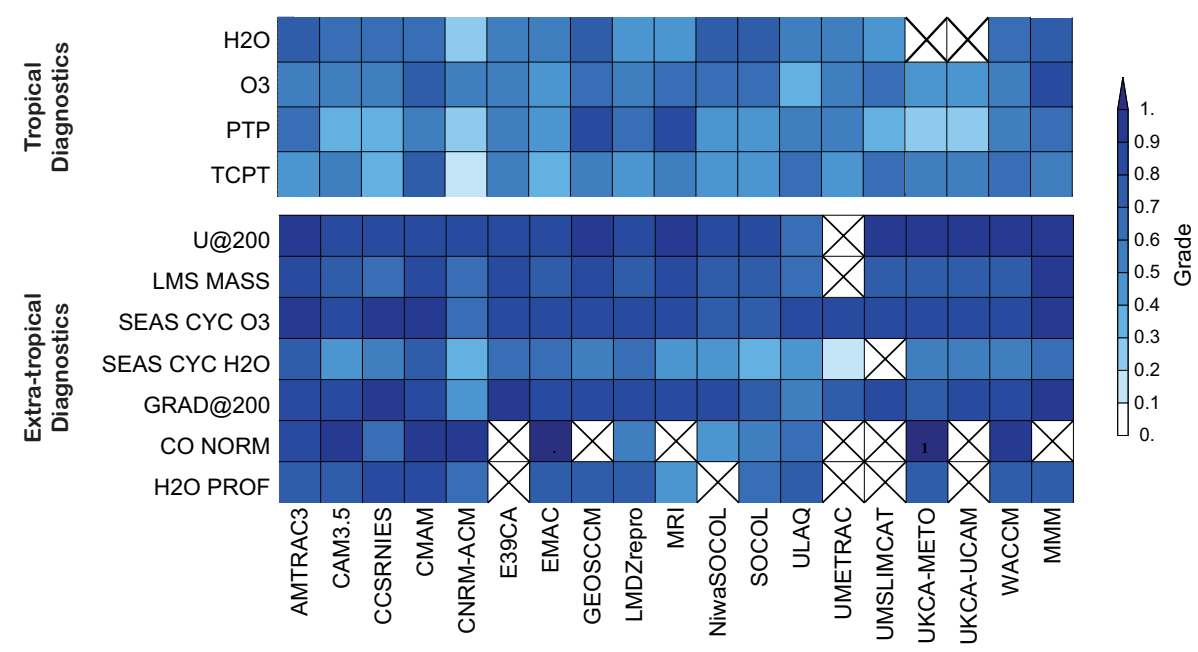

Fig. 9. Quantitative metrics summary from CCMVal-2 models as reported in SPARC-CCMVal (2010), Fig. 7.39. Metrics are produced by the CCMVal diagnostic tool ranging from 0 to 1 for each model. These metrics represent key aspects of the model performance in the upper troposphere and lower stratosphere (UTLS) tropics (upper) and extra-tropics (lower). MMM indicates the multi-model mean. Diagnostics are described in Gettelman et al. (2010) and SPARC-CCMVal (2010). They represent tropical water vapor $\left(\mathrm{H}_{2} \mathrm{O}\right)$, ozone $\left(\mathrm{O}_{3}\right)$, tropopause pressure (PTP) and tropopause temperature (TCPT). Extra-tropical diagnostics are $200 \mathrm{hPa}$ zonal wind (U200), mass of the lowermost stratosphere (LMS MASS), seasonal cycles of $\mathrm{O}_{3}$ and $\mathrm{H}_{2} \mathrm{O}$, the meridional gradient of $200 \mathrm{hPa}$ wind (GRAD200), normalized CO gradients (CO NORM) and $\mathrm{H}_{2} \mathrm{O}$ profile $\left(\mathrm{H}_{2} \mathrm{O}\right.$ PROF). 
use of a known plot type. Modifications and diagnostics can be added to the code repository so others can use them.

We encourage users to modify the code and submit diagnostics and extensions back to the CCMVal-Diag tool archive. Those interested in using the code are referred to the links in Appendix A to obtain the code and further instructions on how to get started.

\section{Appendix A}

\section{Further information}

More information on the standard and the data request to run this tool can be found at

- http://www.pa.op.dlr.de/CCMVal/DataRequests/ CCMVal-2_Datarequest_FINAL.pdf

For general information on the CCMVal project, see

- http://www.pa.op.dlr.de/CCMVal/

This document and the diagnostic code, with latest bug fixes and updates, are available by link from

- http://www.pa.op.dlr.de/CCMVal/CCMVal_ DiagnosticTool.html

Acknowledgements. The development of the CCMVal diagnostic tool was supported by the Atmospheric Chemistry Modeling and Analysis Program (ACMAP) grant NNX08AK54G and by the InfraStructure for the European Network for Earth System Modeling (IS-ENES) project (WP9/JRA3) which is funded by the European Commission under the 7th Framework Programme. Support has also been provided by the National Center for Atmospheric Research (NCAR, USA), the Deutsches Zentrum für Luft- und Raumfahrt (DLR, Germany), the University of Toronto (Canada) and the National Institute for Water and Atmosphere (NIWA, New Zealand). We thank G. Bodeker and the entire staff of Bodeker Scientific for their assistance in planning and developing the tool. We thank S. Tilmes and K.-D. Gottschaldt for comments on this manuscript. NCAR is supported by the United States National Science Foundation. We acknowledge the modeling groups for making their simulations available for this analysis, the Chemistry-Climate Model Validation (CCMVal) Activity for WCRP's (World Climate Research Programme) SPARC (Stratospheric Processes and their Role in Climate) project for organizing and coordinating the model data analysis activity, and the British Atmospheric Data Center (BADC) for collecting and archiving the CCMVal model output.

Edited by: A. Stenke

\section{References}

Brasseur, G. P. and Roeckner, E.: Impact of improved air quality on the future evolution of climate, Geophys. Res. Lett., 32, L23704, doi:10.1029/2005GL023902, 2005.

Cionni, I., Eyring, V., Lamarque, J. F., Randel, W. J., Stevenson, D. S., Wu, F., Bodeker, G. E., Shepherd, T. G., Shindell, D. T., and Waugh, D. W.: Ozone database in support of CMIP5 simulations: results and corresponding radiative forcing, Atmos. Chem. Phys., 11, 11267-11292, doi:10.5194/acp-11-11267-2011, 2011.

Eyring, V., Butchart, N., Waugh, D. W., Akiyoshi, H., Austin, J., Bekki, S., Bodeker, G. E., Boville, B. A., Brühl, C., Chipperfield, M. P., Cordero, E., Dameris, M., Deushi, M., Fioletov, V. E., Frith, S. M., Garcia, R. R., Gettelman, A., Giorgetta, M. A., Grewe, V., Jourdain, L., Kinnison, D. E., Mancini, E., Manzini, E., Marchand, M., Marsh, D. R., Nagashima, T., Newman, P. A., Nielsen, J. E., Pawson, S., Pitari, G., Plummer, D. A., Rozanov, E., Schraner, M., Shepherd, T. G., Shibata, K., Stolarski, R. S., Struthers, H., Tian, W., and Yoshiki, M.: Assessment of temperature, trace species, and ozone in chemistry-climate model simulations of the recent past, J. Geophys. Res., 111, D22308, doi:10.1029/2006JD007327, 2006.

Eyring, V., Chipperfield, M. P., Giorgetta, M. A., Kinnison, D. E., Manzini, E., Matthes, K., Newman, P. A., Pawson, S., Shepherd, T. G., and Waugh, D. W.: Overview of the New CCMVal Reference and Sensitivity Simulations in Support of Upcoming Ozone and Climate Assessments and the Planned SPARC CCMVal Assessment, SPARC Newsletter, 20-26, 2008.

Eyring, V., Cionni, I., Lamarque, J. F., Akiyoshi, H., Bodeker, G. E., Charlton-Perez, A. J., Frith, S. M., Gettelman, A., Kinnison, D. E., Nakamura, T., Oman, L. D., Pawson, S., and Yamashita, Y.: Sensitivity of 21 st century stratospheric ozone to greenhouse gas scenarios, Geophys. Res. Lett., 37, L16807, doi:10.1029/2010GL044443, 2010a.

Eyring, V., Cionni, I., Bodeker, G. E., Charlton-Perez, A. J., Kinnison, D. E., Scinocca, J. F., Waugh, D. W., Akiyoshi, H., Bekki, S., Chipperfield, M. P., Dameris, M., Dhomse, S., Frith, S. M., Garny, H., Gettelman, A., Kubin, A., Langematz, U., Mancini, E., Marchand, M., Nakamura, T., Oman, L. D., Pawson, S., Pitari, G., Plummer, D. A., Rozanov, E., Shepherd, T. G., Shibata, K., Tian, W., Braesicke, P., Hardiman, S. C., Lamarque, J. F., Morgenstern, O., Pyle, J. A., Smale, D., and Yamashita, Y.: Multimodel assessment of stratospheric ozone return dates and ozone recovery in CCMVal-2 models, Atmos. Chem. Phys., 10, 94519472, doi:10.5194/acp-10-9451-2010, 2010b.

Gettelman, A., Hegglin, M. I., Son, S.-W., Kim, J., Fujiwara, M., Birner, T., Kremser, S., Rex, M., Añel, J. A., Akiyoshi, H., Austin, J., Bekki, S., Braesike, P., Brühl, C., Butchart, N., Chipperfield, M., Dameris, M., Dhomse, S., Garny, H., Hardiman, S. C., Jöckel, P., Kinnison, D. E., Lamarque, J. F., Mancini, E., Marchand, M., Michou, M., Morgenstern, O., Pawson, S., Pitari, G., Plummer, D., Pyle, J. A., Rozanov, E., Scinocca, J., Shepherd, T. G., Shibata, K., Smale, D., Teyssédre, H., and Tian, W.: Multimodel assessment of the Upper Troposphere and Lower Stratosphere: Tropics and Trends, J. Geophys. Res., 115, D00M08, doi:10.1029/2009JD013638, 2010.

Knutti, R., Furrer, R., Tebaldi, C., Cermak, J., and Meehl, G.: Challenges in combining projections from multiple models, J. Climate, 23, 2739-2758, 2010. 
Meehl, G. A., Covey, C., Taylor, K. E., Delworth, T., Stouffer, R. J., Latif, M., McAvaney, B., and Mitchell, J. F. B.: The WCRP CMIP3 Multimodel Dataset: A New Era in Climate Change Research, Bull. Am. Meteorol. Soc., 88, 1383-1394, doi:10.1175/BAMS-88-9-1383, 2007.

Morgenstern, O., Giorgetta, M. A., Shibata, K., Eyring, V., Waugh, D. W., Shepherd, T. G., Akiyoshi, H., Austin, J., Baumgaertner, A. J. G., Bekki, S., Braesicke, P., Br,hl, C., Chipperfield, M. P., Cugnet, D., Dameris, M., Dhomse, S., Frith, S. M., Garny, H., Gettelman, A., Hardiman, S. C., Hegglin, M. I., Jöckel, P., Kinnison, D. E., Lamarque, J.-F., Mancini, E., Manzini, E., Marchand, M., Michou, M., Nakamura, T., Nielsen, J. E., Olivié, D., Pitari, G., Plummer, D. A., Rozanov, E., Scinocca, J. F., Smale, D., Teyssédre, H., Toohey, M., Tian, W., and Yamashita, Y.: Review of the formulation of present-generation stratospheric chemistryclimate models and associated external forcings, J. Geophys. Res., 115, D00M02, doi:10.1029/2009JD013728, 2010.

Reichler, T., Dameris, M., and Sausen, R.: Determination of the Tropopause Height from gridded data, Geophys. Res. Lett., 30, 2042, doi:10.1029/2003GL018240, 2003.

SPARC-CCMVal: SPARC Report on the Evaluation of ChemistryClimate Models, SPARC Report 5, WCRP-132, WMO/TD1526, Stratospheric Processes and Their Role In Climate, World Meteorological Organization, 2010.
Taylor, K. E., Stouffer, R. J., and Meehl, G. A.: An Overview of CMIP5 and the Experimental Design, in press, Bull. Amer. Met. Soc, 93, 485-498, doi:10.1175/BAMS-D-11-00094.1, 2012.

Uppala, S., Kallberg, P., Simmons, A., Andrae, U., da Costa Bechtold, V., Fiorino, M., Gibson, J., Haseler, J., Hernandez, A., Kelly, G., Li, X., Onogi, K., Saarinen, S., Sokka, N., Allan, R., Andersson, E., Arpe, K., Balmaseda, M., Beljaars, A., van de Berg, L., Bidlot, J., Bormann, N., Caires, S., Chevallier, F., Dethof, A., Dragosavac, M., Fisher, M., Fuentes, M., Hagemann, S., Holm, E., Hoskins, B., Isaksen, L., Janssen, P., Jenne, R., McNally, A., Mahfouf, J.-F., Morcrette, J.-J., Rayner, N., Saunders, R., Simon, P., Sterl, A., Trenberth, K., Untch, A., Vasiljevic, D., Viterbo, P., and Woollen, J.: The ERA-40 re-analysis, Q. J. R. Meteorol. Soc., 131, 2961-3012, 2005.

Waugh, D. W. and Eyring, V.: Quantitative performance metrics for stratospheric-resolving chemistry-climate models, Atmos. Chem. Phys., 8, 5699-5713, doi:10.5194/acp-8-5699-2008, 2008.

World Meteorological Organization: Scientific Assessment of Ozone Depletion: 2010, WMO Report, World Meteorological Organization, Geneva, 2010. 